\title{
PERCEPÇÃO AMBIENTAL DE DONAS DE CASA SOBRE O USO DE PRODUTOS QUÍMICOS EM DOMICÍLIOS E ESTRATÉGIAS SUSTENTÁVEIS
}

\author{
Georgiana do Amaral Nóbrega \\ Mestre em Físico - Química- UFRN. Especialista em Gestão Ambiental - IFRN \\ E-mail: georgiananobrega@yahoo.com.br \\ Williane Simões Dantas \\ Mestre em Físico - Química- UFRN. Especialista em Gestão Ambiental - IFRN \\ E-mail: willianesimoes@gmail.com.br \\ Valdenildo Pedro da Silva \\ Prof. Dr. em Geografia - IFRN. E-mail: valdenildo.pedro@ifrn.edu.br
}

\section{RESUMO}

Devido ao elevado número de produtos químicos domiciliares que vem sendo consumidos e a escassez de informação sobre os riscos em sua utilização, o homem vem contribuindo consideravelmente para a degradação ambiental. O presente trabalho teve por objetivo analisar a percepção ambiental de donas de casa do bairro de Nova Descoberta na cidade de Natal/RN sobre o uso de produtos químicos domiciliares e disposição de tais produtos, bem como propor estratégias sustentáveis a partir da percepção dessas. A metodologia constituiu na utilização de um instrumento de entrevista, que objetivou analisar como as pessoas dessa investigação científica percebem as mudanças ocasionadas pela utilização e disposição incorreta dos produtos químicos domiciliares e o quanto isso pode afetar a sua qualidade de vida e o meio ambiente. Foi desenvolvido também um levantamento bibliográfico. Foram aplicados 10 instrumentos de entrevista, com donas de casa mantendo um critério conhecido como "saturação" já que os argumentos apresentados em sua grande maioria se repetiam, de forma que não acrescentaria muito ao conteúdo de investigação a persistência na realização de mais entrevistas. A análise dos dados ocorreu por meio de uma abordagem qualitativa e identificação dos principais problemas enfrentados devido à falta de planejamento ambiental domiciliar. A percepção ambiental das donas de casa é a de que utilizam produtos químicos e desconhecem seu uso e disposição corretos. Foi observada a precariedade de informações no bairro da comunidade sobre os malefícios que os produtos químicos domiciliares podem ocasionar e a necessidade da implantação de um planejamento ambiental domiciliar.

Palavras-chave: Percepção Ambiental, Produtos Químicos Domiciliares, Planejamento Ambiental, Sustentabilidade.

\section{ENVIRONMENTAL AWARENESS HOUSEWIVES ON THE USE OF CHEMICALS IN HOUSEHOLDS AND SUSTAINABLE STRATEGIES}

\begin{abstract}
Due to the large number of chemicals at home that has been consumed and the scarcity of information on risks in its use, man has contributed significantly to environmental degradation. This study aimed to analyze the environmental perception of housewives in
\end{abstract}


the neighborhood of New Discovery in Natal / RN on the use of household chemicals and disposal of such products, and propose sustainable strategies from the perspective of those. The methodology consisted in the use of an instrument of the interview, which aimed to analyze how people perceive this research the changes caused by incorrect use and disposal of household chemicals and how it can affect your quality of life and the environment. It was also developed a survey. Instruments were administered 10 interviews with housewives maintaining a criterion known as "saturation" since the arguments presented mostly repeated, so that would not add much to the content of the continuing investigation in conducting more interviews. Data analysis was conducted through a qualitative approach and identifying the main problems faced due to lack of environmental planning at home. The environmental perception of the housewives is that use chemicals and know their correct use and disposal. We observed the scarcity of information in the neighborhood of the community about the harmful effects that chemicals can cause home and need to implement an environmental planning at home.

KEY-WORDS: Environmental Perception, Domiciled Products Chemicals, Sustainability. 


\section{PERCEPÇÃO AMBIENTAL DE DONAS DE CASA SOBRE O USO DE PRODUTOS QUÍMICOS EM DOMICÍLIOS E ESTRATÉGIAS SUSTENTÁVEIS}

\section{INTRODUÇÃO}

O mercado competitivo atual auxiliado pela mídia, com suas propagandas cada vez mais atrativas ajudou no surgimento de uma grande variedade de produtos químicos com formulações diferentes e embalagens mais atrativas estimulando a população a comprá-los. O elevado número de produtos químicos domiciliares consumidos tem contribuído consideravelmente para a degradação do meio ambiente.

Muitos desses produtos, devido ao seu grau de toxidade e utilização inadequada causam problemas de saúde, pois devemos considerar não só as características físico-químicas, a reatividade e a toxicidade, mas também as condições de manipulação, as possibilidades de exposição do indivíduo e as vias de penetração no organismo (SCHVARTSMAN, 1988), bem como a disposição final desses. Muitos produtos usados em residências causam efeitos nocivos e doenças graves, caso sejam utilizados fora das dosagens especificadas, ou do objetivo para o qual tais produtos foram elaborados (GERMANO, P. M.; GERMANO, M. I. S., 2008).

As substâncias químicas tóxicas ocasionam dano temporário ou permanente, podendo causar morte em humanos e animais. As substâncias químicas perigosas causam danos à saúde de seres humanos e outros animais por serem inflamáveis ou explosivas e podem irritar ou danificar a pele ou pulmões, interferir na absorção de oxigênio ou produzir reações alérgicas. Quando as substâncias químicas são potencialmente tóxicas, essas são consideradas mutagênicas, teratogênicas ou carcinogênicas (MILLER, 2007). Muitas dessas substâncias químicas tóxicas e perigosas estão presentes nos produtos químicos de uso domiciliar. A informação e planejamento na utilização desses produtos são essenciais para prevenir acidentes e preservar o meio ambiente (RIBEIRO, 2009).

O descarte de substâncias tóxicas inadequado, tais como pilhas e baterias que apresentam metais pesados em sua composição (chumbo, cádmio e mercúrio) pela população no lixo comum, vem causando sérios problemas ambientais. As baterias enferrujam e vazam poluindo o solo (infiltração), as águas (através das chuvas) e o ar (por evaporação). Além disso, o tempo de decomposição dos metais pesados usados em pilhas e baterias é muito longo.

Outro fator de risco para o meio ambiente é a disposição incorreta de produtos perigosos, tais como lâmpadas de luz fluorescentes (mercúrio na composição), latas de tinta, óleos, solventes e similares que estão sendo descartados no lixo comum devido à carência de informação da população (RIBEIRO, 2009).

O óleo de cozinha usado é geralmente descartado diretamente na pia de muitas residências, que segue para a rede de esgoto comum. Essa prática ocasiona o entupimento de ralos e tubulações. Em cidades que não possuem um sistema de tratamento de esgotos, esses resíduos acabam alcançando rios, lagos ou mar. O contato desses com os mananciais hídricos criam uma camada na superfície da água impedindo a penetração solar, ocasionando a morte da fauna aquática. Muitas vezes o óleo é descartado sobre o solo, impermeabilizando-o e podendo agravar processos de enchente. Quando o óleo descartado 
no solo entra em contato com o sol, há a eliminação de gás metano, o que proporciona a chuva ácida (RIBEIRO, 2009).

Os produtos químicos mais comuns utilizados para limpeza geral nas residências, tais como sabões e detergentes e congêneres atingem sistemas de esgotos e acabam alcançando rios, lagos e praias devido à carência de saneamento básico. Dessa forma, a espuma gerada por tais substâncias atingem as águas se depositando sobre a superfície, impedindo a entrada de oxigênio, podendo causar mortandade de plantas e animais. Os níveis de fosfatos presentes nos detergentes são controlados por lei. A presença dessa substância nas águas de rios, lagos e praias favorecem a multiplicação de algas vermelhas, que em excesso também prejudicam a oxigenação da água causando a eutrofização. A forma de degradação dos detergentes também é fator importante, pois embora no Brasil a lei determine que os detergentes devam ser biodegradáveis, alguns fabricantes não respeitam essa norma (FELICONIO, 2006).

A poluição das águas é resultado não apenas pelo despejo individual de uma substância ou outra, mas também pela reação química resultante da soma dos mais variados produtos de limpeza que usamos em nossas residências, tais como, detergentes, sabão em pó, amaciante, sabonetes, xampus, cremes dentais, desinfetantes, limpa-vidros, água sanitária (com $2 \%$ de cloro ativo), amoníaco, entre outros. Essa mistura de produtos potencializa os impactos sobre a qualidade das águas, sobre a fauna e flora dos ecossistemas aumentando o perigo para as populações que consumirem estas águas ou se alimentarem desses animais aquáticos posteriormente (BRANCO, 1990).

Considerando essa contextualização descrita, sobre os riscos que os produtos químicos tóxicos e perigosos domiciliares apresentam para o homem e o meio ambiente, o presente trabalho procurou responder a seguinte indagação: Que percepção ambiental as donas de casa, do bairro de Nova Descoberta na cidade de Natal/RN, têm sobre à utilização e disposição dos produtos químicos de uso domiciliar? Que estratégias sustentáveis podem ser produzidas para minimizar os impactos causados a saúde e ao meio ambiente dessas pessoas?

Para responder as questões levantadas foi realizado um trabalho bibliográfico e uma pesquisa direta; por meio da aplicação de uma entrevista estruturada. Entrevistou-se 10 donas de casas. Esse número foi considerado importante e adequado para essa pesquisa por satisfazer o critério de "saturação". Esse critério consiste em realizar as entrevistas até o momento em que se percebe que não estão sendo obtidas informações novas (SÁ, 1998).

A pesquisa teve natureza aplicada, pois objetiva identificar a percepção, sobre os riscos da utilização dos produtos químicos domiciliares. Assim como, diagnosticar, avaliar os impactos e propor medidas mitigadoras (corretivas e preventivas) de modo a contribuir para preservação do meio ambiente. A pesquisa foi realizada por meio de um estudo de caso de algumas casas do bairro de Nova Descoberta. Esse tipo de estudo se caracteriza por ser um procedimento técnico profundo de um ou poucos objetos, de maneira que se permita a obtenção de um conhecimento amplo e detalhado. Este estudo contribui para explorar a vida real, cujos limites não são bem definidos e são realizados e investigados para explicar variáveis causais que não possibilitam a utilização de levantamentos e experimentos (SILVA, 2009). 
Trata-se de estudo de caráter qualitativo, pois esse faz relação entre o mundo real e a subjetividade que não pode ser traduzida ou explicada através de números. Esse tipo de investigação leva em consideração a realidade social como fonte principal da coleta de informações e o pesquisador como instrumento-chave da investigação (SILVA, 2009).

O plano de trabalho proposto para a realização do planejamento ambiental foi organizado em cinco fases, conforme Rodrigues (1997):

Fase Organizacional: objetiva identificar os principais conflitos ambientais na área de estudo, ou seja, nas residências de donas de casa do Bairro de Nova Descoberta na cidade de Natal/RN, de forma a expressar os recursos, impactos e conflitos relativos às questões levantadas no planejamento ambiental, para definir a abrangência temporal a ser considerada.

Fase de Inventário: objetiva selecionar indicadores ambientais com base nas premissas de sustentabilidade e os temas identificados na fase organizacional.

Fase de Diagnóstico Ambiental: objetiva propor um modelo de organização residencial, com a elaboração de planos para promover as soluções dos problemas,

Fase Propositiva: objetiva propor as soluções dos problemas, considerando a identificação dos problemas, conflitos, potencialidades e fragilidades ambientais.

Fase Executiva: objetiva viabilizar os cenários alternativos voltados à reabilitação ambiental, e formulação das diretrizes que apontam sequiência, temporalidade, instrumentos, estratégias e competências a ser executada a cada ação alternativa proposta.

A partir da percepção de donas de casa do bairro em estudo, quanto ao uso inadequado de tais produtos, as entrevistas aplicadas objetivaram contribuir positivamente para que a população perceba a necessidade da realização de um planejamento ambiental domiciliar. Esse planejamento deverá contribuir para a criação de estratégias para minimizar a produção de lixo domiciliar e os danos causados ao meio ambiente.

\section{CARACTERIZAÇÃO DO BAIRRO EM ESTUDO: NOVA DESCOBERTA}

O bairro de Nova Descoberta está localizado na região sul da cidade de Natal pertencente ao Estado do Rio Grande do Norte. De acordo com os dados do censo do Instituto Brasileiro de Geografia e Estatística (IBGE) do ano de 2000, a região sul de Natal possui 155.882 habitantes, correspondendo a $22 \%$ da população de Natal.

Os limites do bairro correspondente (Figura 1) são: ao norte Tirol, ao sul Parque das Dunas e Lagoa Nova, ao leste Parque das Dunas e oeste Lagoa Nova (SEMURB, 2010). 


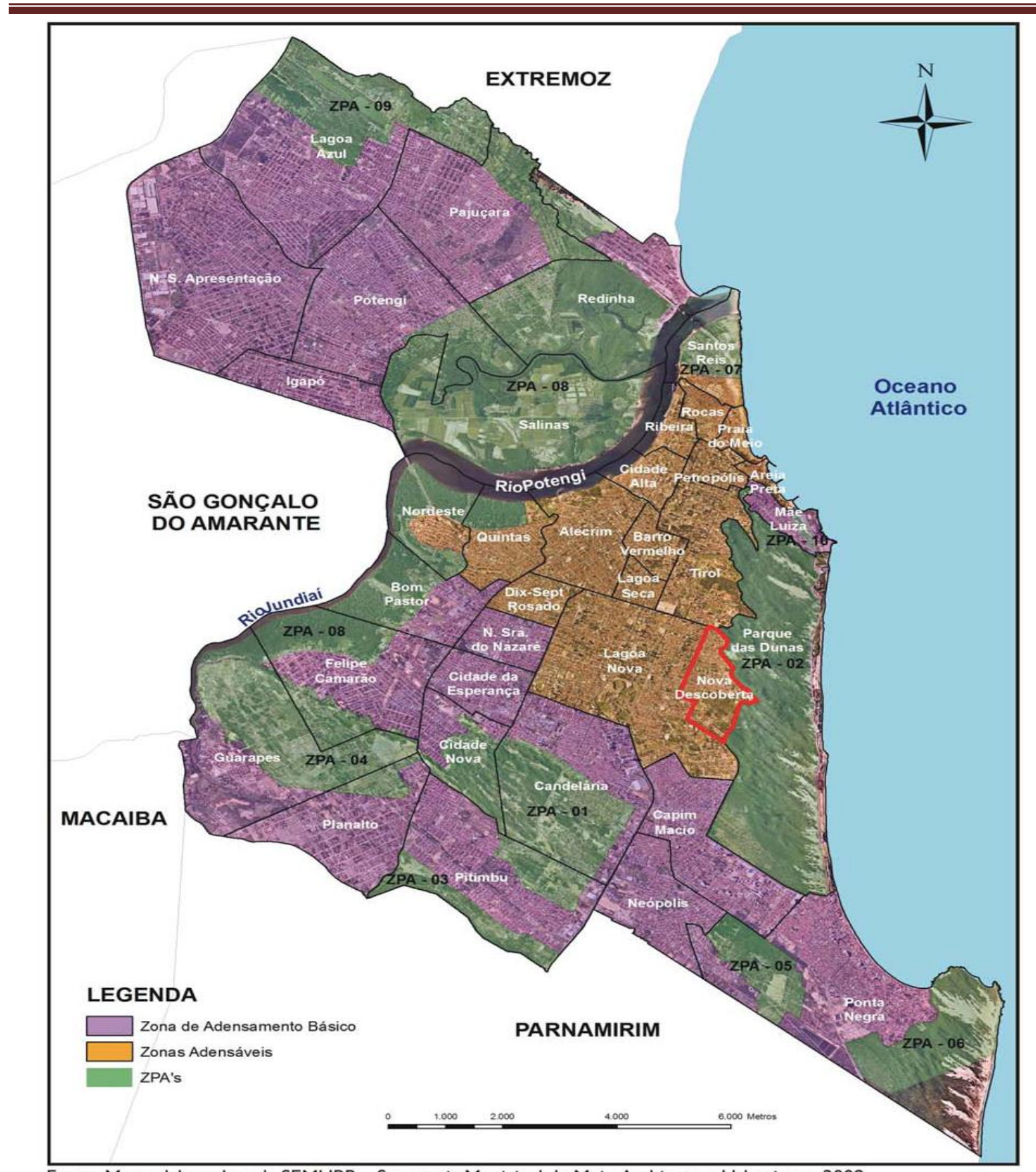

Fonte: Mapa elaborado pela SEMURB - Secretaria Municipal de Meio Ambiente e Urbanismo, 2009.

Figura 1: Localização do Bairro de Nova Descoberta.

Esse trabalho pretende também despertar a visão dos leitores sobre os questionamentos e indagações feitos e analisar através das respostas destes a percepção dos entrevistados.

Dessa forma, os leitores deverão ser capazes de refletir sobre os riscos e prevenções a serem tomados na utilização dos produtos químicos de uso domiciliar e através das questões ambientais levantadas perceber a necessidade do planejamento domiciliar para que esses produtos sejam utilizados e destinados de forma adequada promovendo a prevenção de acidentes e evitando determinados problemas de saúde e ambientais causados por substâncias tóxicas a fim de alcançar a sustentabilidade. 
A utilização do planejamento ambiental ordenado como ferramenta começando pela nossa residência servirá de base para que esta conduta seja colocada em prática nos demais ambientes, através de atitudes que possam atingir o desenvolvimento sustentável.

A informação sobre a toxidade, armazenamento e manuseio correto dos principais produtos químicos de uso domiciliar, boas práticas ambientais, tais como correta disposição de resíduos sólidos perigosos, são essenciais para um bom planejamento domiciliar e preservação do meio ambiente e estão descritas na fundamentação teórica.

A participação da sociedade é de extrema importância para se alcançar a sustentabilidade lembrando sempre que todos têm responsabilidade social quanto às questões de preservação do meio ambiente.

As donas de casa do bairro de Nova Descoberta foram estimuladas através das entrevistas realizadas a observarem e refletirem sobre os maus hábitos ambientais realizados pela comunidade quanto ao uso inadequado e disposição incorreta dos produtos químicos de uso domiciliar. Dessa forma, essas foram capazes de avaliar a necessidade do planejamento ambiental em suas residências.

O meio ambiente deve ser visto pela comunidade do bairro de Nova Descoberta e por todos como um sistema, onde o homem também faz parte dele e é responsável pela sua preservação.

\section{FUNDAMENTAÇÃO TEÓRICA}

A percepção ambiental pode ser entendida como o produto das reações e dos sentidos diante do meio que cerca o individuo, possibilitando o seu raciocínio, a definição de valores, sentimentos, reações e interações positivas ou negativas sobre o meio ambiente. A partir dessa percepção, o individuo interage com o mundo, influencia seus pares, intervém no ambiente, caminha na direção do processo de conhecimento e do exercício da cidadania ambiental (FERNANDES et al., 2009).

\section{PERCEPÇÃO AMBIENTAL}

O termo "percepção" é definido como o entendimento entre o sujeito e o que está externo a ele. É a relação existente entre os indivíduos e o meio ambiente o qual estão inseridos. A paisagem provém da percepção da relação existente entre a subjetividade e a objetividade (TERAMUSSI, 2008).

A percepção é o entendimento entre o indivíduo e o que está exterior a ele. Através dela é possível fazer relações sobre a historicidade em relação a um dado espaço. Os processos perceptivos diferem de acordo com o contexto sociocultural no qual o individuo está inserido, pois a percepção está diretamente ligada à sua cultura. Desta forma, cada grupo social percebe os objetos e os codificam de acordo com a sua ótica (TERAMUSSI, 2008).

A percepção ambiental é compreendida geralmente, como a resposta aos estímulos externos, que possuem relação com o contexto sócio-cultural do indivíduo e a partir de uma cadeia de associações feitas, esse indivíduo seja capaz de atribuir valores positivos ou negativos ao local (TUAN, 1980). 
A percepção ambiental já é estudada em diversas áreas, dentre elas: psicologia, geografia, biologia e antropologia objetivando entender os fatores, mecanismos e processos que levam ao indivíduo a formação de sua opinião e através da mesma ter atitudes em relação ao meio em que estão inseridos (TERAMUSSI, 2008).

Os estudos realizados de percepção ambiental procuram investigar as relações que uma dada comunidade tem com o meio ambiente em que vive, observando relações de ordem cognitiva, afetiva e ética. Estuda também a forma como pensa, sente e age uma determinada comunidade, no âmbito da vida que pode ser obtida no campo da percepção ambiental (TERAMUSSI, 2008).

As percepções por serem objetos subjetivos podem variar de indivíduo para indivíduo, porém, suas representações coletivas de lugar e de território transmitem o modo como se vive e planeja o espaço em uma relação discursiva entre o espaço político, o território e o pensamento sobre esse espaço. Tendo em vista que o conhecimento do mundo físico não é apenas perceptivo, mas também representativo, esse conhecimento não está apenas inserido nas atividades de observação científica sobre o ambiente, mas também através de mitos, histórias e festas populares (TERAMUSSI, 2008).

Para os estudos de percepção ambiental, as percepções biofisiológicas também são incluídas; as imagens as quais formamos do mundo vivido, memórias, experiências, predileções, interpretações, julgamentos e expectativas (DEL RIO, 1996). A percepção está ligada a elementos internos e externos da experiência e é obtida a partir da expressão humana sobre sua realidade ambiental por intermédio de suas experiências e expectativas (FERREIRA, 2005).

\section{SUSTENTABILIDADE}

A sustentabilidade baseia-se na conciliação entre o desenvolvimento integral, preservação do meio ambiente e a melhoria da qualidade de vida que constituem as metas para se alcançar a sustentabilidade (MILARÉ, 2009).

Um dos movimentos que contribuiu de forma efetiva para o desenvolvimento sustentável foi à Conferência das Nações Unidas sobre o Meio Ambiente e Desenvolvimento CNUMAD em 1992, mais conhecido como Rio-92 ou ECO-92. O mesmo adotou na Agenda 21 o desenvolvimento sustentável como meta a ser alcançada e obedecida por todos os países. Dessa forma, o principio 4 desse movimento, estabelece que, para alcançar o desenvolvimento sustentável, a proteção ambiental constituirá parte integrante do processo de desenvolvimento e não poderá ser considerada isoladamente (MILARÉ, 2009).

Conciliar desenvolvimento com meio ambiente significa levar em consideração os problemas ambientais dentro de um processo contínuo de planejamento, adequando-se as exigências de ambos, considerando suas inter-relações dentro de um contexto sociocultural, político, econômico e ecológico através de uma relação determinada e definida de tempo e espaço (MILARÉ, 2009).

\section{ESTRATÉGIAS SUSTENTÁVEIS}

Estratégias sustentáveis são ações que o indivíduo cria para resolver problemas em nossa sociedade, ou em qualquer outro lugar, em um determinado prazo de educação capaz de 
nutrir uma visão e um caminho para um futuro sustentável, justo e satisfatório (SUSTAINABLE STRATEGIES, 2010).

A importância das escolhas pessoais e das ações individuais que são promovidas contribui para formação da nossa sociedade e muitas vezes são subestimadas. Deve-se levar em consideração a necessidade do funcionamento das comunidades que promovem $\mathrm{o}$ desenvolvimento através do potencial individual (SUSTAINABLE STRATEGIES, 2010).

A etapa inicial para a revitalização da comunidade em que vivemos é a criação de ambientes de aprendizagem que possibilitem explorar e desenvolver o equilíbrio entre o conjunto e o indivíduo na comunidade (SUSTAINABLE STRATEGIES, 2010).

As estratégias sustentáveis oferecem uma abordagem holística e integral, bem como suficiência em desenvolvimento para enfrentar os desafios do mundo contemporâneo (SUSTAINABLE STRATEGIES, 2010).

As estratégias são ações que visam diminuir as pressões sobre o ambiente. São resultantes da produção e do consumo dos recursos naturais sem prejudicar o desenvolvimento econômico. Seu objetivo é reduzir os impactos ambientais negativos provocados pela utilização dos recursos naturais (esgotamento dos recursos e poluição), respeitando os objetivos do crescimento econômico. A estratégia abrange todos os setores consumidores de recursos e implica melhorar o rendimento dos recursos, reduzir a sua incidência no ambiente e substituir os recursos muito poluentes por outras soluções com o propósito de alcançar a sustentabilidade (EUROPA.EU, 2010).

\section{PLANEJAMENTO AMBIENTAL}

A ferramenta utilizada para pensar e projetar o futuro é o planejamento, o qual viabiliza as decisões sobre ações humanas objetivando governar o futuro de maneira estratégica, baseando-se na capacidade de previsão como preparação, visando a criação de um futuro desejado a partir das possibilidades verificadas no presente.

Segundo Chardwick (1973), o planejamento é um sistema conceitual geral que usa o método analógico para elaborar um sistema conceitual independente, mas que corresponda ao mundo real viabilizando a busca da compreensão dos fenômenos do processo, antecipando-se a eles e avaliando-os. Por intermédio da otimização do sistema conceitual, indiretamente pode-se inferir a otimização do sistema no mundo real. Estas representações são denominadas de modelos. Considerando que o mundo real se encontra imerso em processos contínuos de mudança é necessário que os modelos evoluam para compreensão e predição dessas mudanças futuras sobre a base do entendimento do passado.

De acordo com Santos (2004), o planejamento é necessário na adequação de ações a potencialidade, vocação local e à sua capacidade de suporte, buscando o desenvolvimento sustentável e harmônico da região e a manutenção da qualidade do ambiente físico, biológico e social.

O planejamento ambiental enfoca o ambiente biofísico onde vivem as pessoas e comunidades, e analisa os efeitos de atividades de desenvolvimento e de outros planejamentos (SLOCOMBE, 1993). 
De acordo com Franco (2001), o planejamento ambiental é descrito como aquele que parte do princípio da valoração e conservação das bases naturais de um dado território como base de auto-sustentação da vida e das interações que a mantém, ou seja, das relações ecossistêmicas, onde são pressupostos três princípios de ação humana sobre os ecossistemas: os princípios da preservação, da recuperação e da conservação do meio ambiente.

Os planejamentos ambientais são organizados dentro de uma estrutura que envolve pesquisa, análise e síntese. A pesquisa tem o objetivo de reunir e organizar dados para facilitar sua interpretação. Os dados organizados são avaliados, para atingir a compreensão do meio estudado, com seus acertos e conflitos, constituindo a fase de análise. A síntese refere-se à aplicação dos conhecimentos alcançados para a tomada de decisões. De forma geral, o planejamento é um processo elaborado em fases que evoluem sucessivamente, e o resultado de uma é a base ou os princípios para o desenvolvimento da fase seguinte (SANTOS, 2004).

O processo de planejamento ambiental engloba uma série de etapas e procedimentos interrelacionados que se assemelham aos demais tipos de planejamento. Esse planejamento é dividido em cinco etapas que são: o reconhecimento de uma situação problema; o diagnóstico ambiental e a análise da situação ou problema; a fixação de objetivos e metas a alcançar; a formulação das ações e a estruturação do plano de gestão; a implementação, monitoria e avaliação do plano de gestão (PHILLIPPI, 2005).

O plano de gestão, no planejamento ambiental, é o produto do processo de planejamento, sendo este um instrumento de gestão ambiental aplicado ao território onde se planeja atingir determinados objetivos. Este deve estabelecer ações de proteção e conservação da biodiversidade e a implementação de diretrizes para o desenvolvimento econômico e social compatíveis com o desenvolvimento sustentável dos recursos naturais (PHILLIPPI, 2005).

\section{SUBSTÂNCIAS QUÍMICAS (AGENTE QUÍMICO, AGENTE TÓXICO, TOXICANTE, SUBSTÂNCIA TÓXICA, XENOBIÓTICO)}

É todo o agente que contém uma atividade potencial intrínseca, capaz de interferir em um sistema biológico levando a um dano, lesão ou injúria, quando absorvido pelas vias de penetração. A atividade de uma substância química é resultado de alguns fatores tais como: dose, formulação, via de penetração, duração da exposição, e interação com outras substâncias químicas.

As substâncias químicas podem ser classificadas de várias formas, onde sua forma mais simples de classificação é quanto ao seu estado físico (MICHEL, 2000). A forma da substância pode interferir em seu efeito potencial intrínseco. Quando se apresentam na forma gasosa, vapores ou líquido volátil, por exemplo, são absorvidos facilmente pela via respiratória.

Substância química, segundo o National Institute for Occupatonal Safery and Helth (NIOSH-EUA), são aquelas que apresentam potencial tóxico capaz de causar: irritação ou hipersensibilidade da pele, das membranas mucosas, dos olhos, e das vias respiratórias, câncer, mutações genéticas, más formações congênitas, diminuição ao estado de alerta ou alterar o comportamento humano, morte em animais de experimentação por diversas vias de penetração, dano à saúde do homem, levando a lesão reversível ou irreversível 
produzindo perigo para vida, ou morte, pelas vias de absorção, em qualquer concentração ou quantidade e em qualquer tempo de exposição (MICHEL, 2000).

\section{SUBSTÂNCIAS QUÍMICAS TÓXICAS E PERIGOSAS}

As substâncias químicas tóxicas são aquelas que podem causar dano temporário ou permanente, morte em humanos e animais. Já as substâncias químicas perigosas podem causar danos a saúde de seres humanos ou outros animais. Quando as substâncias químicas são potencialmente tóxicas são consideradas mutagênicas, teratogênicas ou carcinorgênicas (MILLER, 2007).

As mutagênicas são substâncias químicas que causam ou aumentam a freqüência de mutações ou mudanças nas moléculas de DNA. O ácido nitroso $\left(\mathrm{HNO}_{2}\right)$, formado pela digestão de conservantes de nitrito nos alimentos é um exemplo de mutagênico. Mutações prejudiciais que ocorrem nas células reprodutivas podem ser transmitidas aos descendentes e futuras gerações. Não existe limiar seguro de exposição aos mutagênicos.

As substâncias teratogênicas são aquelas que causam danos a saúde ou defeito de nascimento no feto ou embrião. O álcool etílico é uma substância teratogênica. Beber durante a gestação pode resultar em danos físicos, mentais e de desenvolvimento do bebê (MILLER, 2007).

As substâncias químicas ou radiações ionizantes que podem causar o câncer são denominadas de carcinogênicas. O benzeno é uma dessas substâncias, o qual é bastante utilizado como solvente químico. Outro exemplo é o formaldeído (formol), um poluente atmosférico presente no interior de residências, por ser usado na fabricação de materiais de uso doméstico, como madeira compensada, chapa de madeira aglomerada, assoalho, móveis e cola para carpete e papel de parede (MILLER, 2007).

Os produtos químicos perigosos são classificados de acordo com a Tabela1 (MICHEL, 2007):

Tabela1: Classificação dos Produtos Químicos Perigosos.

\begin{tabular}{|c|c|c|c|}
\hline CLASSE 1 & \multicolumn{3}{|c|}{ Explosivos } \\
\hline \multirow[t]{2}{*}{ CLASSE 2} & Classe 2.1 & Classe 2.2 & Classe 2.3 \\
\hline & $\begin{array}{c}\text { Gases } \\
\text { inflamáveis }\end{array}$ & $\begin{array}{l}\text { Gases não- } \\
\text { inflamáveis } \\
\text { comprimidos }\end{array}$ & Gases tóxicos \\
\hline CLASSE 3 & \multicolumn{3}{|c|}{ Líquidos inflamáveis } \\
\hline \multirow[t]{2}{*}{ CLASSE 4} & Classe 4.1 & Classe 4.2 & Classe 4.3 \\
\hline & $\begin{array}{l}\text { Sólidos } \\
\text { inflamáveis }\end{array}$ & $\begin{array}{l}\text { Espontâneamente } \\
\text { combustíveis }\end{array}$ & $\begin{array}{l}\text { Perigosos quando } \\
\text { molhados }\end{array}$ \\
\hline \multirow[t]{2}{*}{ CLASSE 5} & Classe 5.1 & \multicolumn{2}{|c|}{ Classe 5.2} \\
\hline & $\begin{array}{l}\text { Agentes } \\
\text { oxidantes }\end{array}$ & \multicolumn{2}{|c|}{ Peróxidos orgânicos } \\
\hline \multirow[t]{2}{*}{ CLASSE 6} & Classe 6.1 & \multicolumn{2}{|c|}{ Classe 6.2} \\
\hline & Tóxicos & \multicolumn{2}{|c|}{ Infecciosos } \\
\hline CLASSE 7 & \multicolumn{3}{|c|}{ Radioativos } \\
\hline CLASSE 8 & \multicolumn{3}{|c|}{ Corrosivos } \\
\hline CLASSE 9 & \multicolumn{3}{|c|}{ Miscelânea } \\
\hline
\end{tabular}

Fonte: (MICHEL, 2007) 


\section{TOXICOLOGIA}

Por toxicologia, entende-se como sendo a capacidade latente, inerente, que uma substância química possui, ou seja, é a medida do potencial tóxico de uma substância. Não existem substâncias químicas atóxicas que não tenham efeitos lesivos ao organismo. Porém, tais substâncias podem ser utilizadas de forma segura, pela limitação da dose e da exposição ao organismo humano (MICHEL, 2000).

O dano causado pela exposição de um indivíduo a uma determinada substância química depende da quantidade de exposição (dosagem), da freqüência de exposição, da eficácia dos sistemas de desintoxicação do corpo e da composição genética do indivíduo (MILLER, 2007).

Toxidade é a medida dos efeitos nocivos que uma determinada substância pode causar, como ferimentos, doenças ou morte de um organismo vivo. Esta medida depende de diversos fatores, tais como: dosagem (quantidade ingerida, inalada ou absorvida pela pele do individuo); frequiência de ocorrência da exposição; quem é exposto (adulto, criança, por exemplo) e eficácia dos sistemas de desintoxicação (fígado, pulmões e rins) do organismo. A genética também é um desses fatores, que determina a sensibilidade de uma pessoa a uma determinada toxina em particular. Algumas pessoas são sensíveis a várias toxinas, ou seja, possuem sensibilidade química múltipla (SQM). Essa variação genética nas pessoas individuais à exposição de várias toxinas provoca uma complexa questão ética, política e econômica no que tange a regulação dos níveis de uma substância tóxica no meio ambiente (MILLER, 2007).

Alguns fatores podem afetar o dano causado por uma substância. Dentre eles, destacam-se as interações químicas que podem aumentar ou multiplicar os efeitos nocivos de uma substância e a solubilidade, pois as toxinas solúveis em água (geralmente compostos inorgânicos) podem se deslocar pelo meio ambiente atingindo a rede de abastecimento de águas e soluções aquosas que envolvem células no corpo. Já as toxinas solúveis em óleos ou gorduras (geralmente compostos orgânicos) podem penetrar nas membranas que envolvem as células e se acumular nos tecidos e células do corpo.

Outro fator é a persistência ou resistência a decomposição de uma substância no meio ambiente que pode significar efeitos nocivos de longa duração sobre a saúde de pessoas e seres vivos como é o caso do Dicloro-Difenil-Tricloetano (MILLER, 2007).

O dano causado por uma substância pode ser intensificado também pela bioacumulação, na qual algumas moléculas são absorvidas e armazenadas em órgãos e tecidos específicos em níveis maiores que os normais. Dessa forma, uma substância química mesmo encontrada no ambiente em baixas concentrações pode se acumular em um determinado órgão e tecidos em nível nocivo (MILLER, 2007).

Além disso, quando os níveis de algumas toxinas potenciais no meio ambiente podem ser aumentados à medida que percorrem as cadeias alimentares, pode ocorrer o fenômeno da biomagnificação. Os organismos nos níveis tróficos baixos podem consumir pequenas quantidades de uma dada toxina, porém cada animal no nível subseqüente estará ingerindo quantidades cada vez maiores dessas toxinas (MILLER, 2007).

O tipo e a extensão do dano à saúde devido à exposição a um agente químico ou outro tipo de agente é denominado de fator resposta. A resposta prejudicial à exposição imediata ou 
rápida variando de tontura à morte é denominada de efeito agudo. $\mathrm{O}$ efeito crônico é uma conseqüência permanente ou de longa duração que promovem, por exemplo, danos em rins ou fígado em resposta a uma única exposição ou pequenas doses repetidas de uma substância prejudicial (MILLER, 2007).

$\mathrm{Na}$ verdade, qualquer substância química sintética ou natural pode ser prejudicial se ingerida em quantidade grande o suficiente, mas existem mecanismos de defesa que o corpo humano dispõe para reduzir os efeitos nocivos de algumas substâncias químicas. (MILLER, 2007).

Um método para determinar as toxidades relativas de várias substâncias químicas é medir seus efeitos em animais de testes. Dessa forma podemos determinar a dose letal (DL) de uma substância. A dose letal média (DL50) de uma substância química é a quantidade recebida nessa dose que mata 50\% dos animais (camundongos e ratos) em uma população de teste em um período de 14 dias (MILLER, 2007). Os efeitos das substâncias químicas sobre o organismo humano foram evidenciados em pesquisas realizadas em 1970, sobre animais selvagens e de laboratório, juntamente com alguns estudos epidemiológicos sugerem que a exposição a algumas substâncias químicas por um tempo prolongado mesmo em pequenas doses pode causar danos ao sistema imunológico, nervoso e endócrino (MILLER, 2007).

\section{PRODUTOS SANEANTES}

Os produtos saneantes são aqueles utilizados na limpeza e conservação de ambientes. Esses são importantes na limpeza de residências ou quaisquer outros locais, pois eliminam as sujeiras, germes, bactérias, evitando desta forma o aparecimento de doenças ocasionadas pela falta de higienização dos ambientes. Os principais exemplos de saneantes são: detergentes líquido, detergente em pó e sabão, cera, água sanitária, inseticidas, repelente de insetos e raticida, desinfetantes (ANVISA, 2010).

Existem produtos saneantes clandestinos que são aqueles cuja venda é feita sem permissão do Ministério da Saúde. Esses produtos não proporcionam aos consumidores a garantia de sua eficiência e na maioria das vezes não eliminam os germes e nem limpam direito, pois não possui em sua formulação ingredientes próprios e quando os contém não se apresentam nas concentrações corretas. Por não haver nenhum controle na formulação desses produtos, podem ser causados sérios danos à saúde humana (ANVISA, 2010).

Os saneantes clandestinos são vendidos, geralmente, por ambulantes em caminhões, peruas, de porta em porta. A melhor maneira de reconhecer um produto clandestino é examinando seu rótulo, o qual deverá conter: o nome do fabricante ou importador, com endereço completo, telefone e nome do técnico responsável; a frase produto notificado pela Agência Nacional de Vigilância Sanitária (ANVISA) ou número do registro no ministério da saúde; informações no rótulo; avisos sobre os perigos e informações de primeiros socorros; o número telefônico do serviço de atendimento ao consumidor (ANVISA, 2010).

\section{PRODUTOS TÓXICOS DOMICILIARES}

Os resíduos sólidos são classificados de acordo com as Normas Técnicas (ABNT) em perigosos, não inertes (lixo orgânico como resto de alimentos) e inertes (de difícil 
decomposição). Esta classificação é necessária para destinar o lixo de maneira ambientalmente correta, separando os resíduos perigosos dos demais resíduos já que esses requerem maior rigor no monitoramento e controle (NBR 10004: 2004).

Inúmeros produtos de uso domiciliar são considerados perigosos (lixo tóxico), dentre eles, as lâmpadas fluorescentes, latas ou resto de tintas, óleos, solventes e similares, pilhas e baterias, medicamentos impróprios para o consumo (prazo de validade vencido) termômetros, dentre outros. Esses produtos oferecem riscos e danos para o meio ambiente (CECOVISA, 2006).

As lâmpadas fluorescentes apresentam em sua composição substâncias como mercúrio, que é um metal pesado que quando ingerido ou inalado (vapores) causa efeitos nocivos a saúde dos seres humanos e animais. Quando essas estão intactas não oferece perigo ao meio ambiente, porém quando são quebradas liberam vapores de mercúrio, que pode ser absorvido (via respiratória), principalmente pelos pulmões causando problemas respiratórios (CECOVISA, 2006).

As pilhas e baterias apresentam substâncias bastante tóxicas em sua composição. As pilhas comuns contêm zinco, manganês e cloreto de amônia. Já as pilhas alcalinas apresentam além desses metais, cádmio, níquel, chumbo e algumas possuem até mercúrio, embora haja uma tendência dos fabricantes reduzirem as quantidades desses materiais (CECOVISA, 2006).

As latas de tintas ou resto de tintas, óleos, solventes e similares são produtos inflamáveis e caso esses sejam aspirados, podem ocasionar pneumonias químicas, problemas no sistema nervoso, no estômago e intestino. Os pigmentos e corantes apresentam metais pesados como chumbo, cádmio e outros, além de solventes aromáticos (benzeno, tolueno dentre outros) que apresentam grande toxidade. Os medicamentos impróprios para o consumo e/ou com data de validade vencida possuem elementos tóxicos os quais podem causar envenenamento, intoxicações e outros danos aos seres humanos (CECOVISA, 2006).

Os termômetros comuns muito utilizados pela população são exemplos de outros produtos que possuem mercúrio metálico. A liberação desse produto tóxico ocorre quando se quebra o mesmo. Essa substância pode ser absorvida pela pele ou inalada causando inúmeras complicações para saúde. O mercúrio presente em lâmpadas fluorescentes, tintas, pilhas, baterias e termômetros provocam alterações no metabolismo, danos aos rins e sistema respiratório, afeta o cérebro e sistema neurológico, causa inflamação na gengiva, boca, irritações na pele e nas mucosas (CECOVISA, 2006).

O cádmio presente nas pilhas e baterias pode provocar câncer, dores reumáticas, hipertensão, disfunção renal e nas articulações. O zinco presente em pilhas e tintas ocasiona irritação no aparelho digestivo e respiratório e deterioração dos dentes. Já o manganês presente na composição de pilhas, tintas e medicamentos causa uma desordem crônica do sistema nervoso central, bronquite e pneumonia (CECOVISA, 2006).

Na composição das baterias de celulares é encontrado níquel, uma substância tóxica que causa irritação crônica do aparelho respiratório, bronquite asmática, aumenta o risco de câncer. $\mathrm{O}$ chumbo encontrado na composição de pilhas e tintas pode ocasionar perda de memória, lentidão de raciocínio, anemia, distúrbios digestivos, redução da fertilidade (CECOVISA, 2006). 
O cloreto de amônia presente nas pilhas acumula-se no organismo e provoca asfixia. Também é encontrado lítio na composição dessas, substância que causa irritação no sistema nervoso central, visão turva, vertigens, ruídos nos ouvidos (CECOVISA, 2006).

Os resíduos tóxicos domiciliares não devem ser dispostos no lixo comum. As lâmpadas florescentes devem ser vedadas nas extremidades e acondicionadas em caixas de papelão ou protegidas com jornal ou plástico-bolha para evitar que quebrem. As latas de tinta, óleos, solventes e similares devem ser acondicionados de forma segura para evitar que derramem. Para obter informação sobre o local para onde esses resíduos devem ser enviados, as pessoas podem entrar em contato com as companhias de limpeza ou Secretaria do Meio Ambiente de seu município. As pilhas e baterias de acordo com a resolução do Conselho Nacional do Meio Ambiente- CONAMA n ${ }^{\circ} 401$ de 4 de novembro de 2008 devem ser devolvidas aos fabricantes e vendedores autorizados após a extinção de sua carga (CONAMA, 2010).

A legislação regula o descarte dos resíduos perigosos através da Lei dos Crimes Ambientais $\mathrm{n}^{\circ}$ 9.605, de 13 de fevereiro de 1998 e considera pessoas físicas e jurídicas e sujeito à pena de multa ou detenção quem: produzir, processar, importar, exportar, comercializar, fornecer, transportar, armazenar, guardar, ter em depósito ou usar o produto ou substância tóxica, perigosa ou nociva à saúde humana ou ao meio ambiente, em desacordo com as exigências estabelecidas em leis ou nos seus regulamentos. Ainda no Parágrafo $1^{\circ}$ da referida lei discorre que nas mesmas penas, incorre quem abandona os produtos ou substâncias referidas no caput, ou os utiliza em desacordo com as normas de segurança (Art.56) (CECOVISA, 2006).

Sobre o manejo, descarte e disposição final de tintas, solventes e similares não existe legislação específica. Apenas a resolução $\mathrm{n}^{\circ} 401$ de 4 de novembro de 2008, do CONAMA, disciplina o descarte e gerenciamento ambiental adequado de pilhas e baterias usadas. Esta resolução determina que os fabricantes e importadores sejam responsáveis pela coleta, armazenamento, transporte, reutilização, reciclagem, tratamento e disposição final ambientalmente adequada (CONAMA, 2010).

Em relação aos medicamentos existe a resolução de $n^{\circ} 5$ de agosto de 1993 do CONAMA, que discorre sobre o gerenciamento de resíduos sólidos de serviços de saúde (CONAMA, 2010).

\section{PRINCIPAIS PRODUTOS QUÍMICOS DOMICILIARES}

A segurança no manuseio e a informação sobre a toxidade e disposição final dos principais produtos químicos domiciliares são essenciais para evitar uma série de problemas tanto na saúde dos seres humanos quanto na preservação do meio ambiente.

Os principais produtos químicos domiciliares serão apresentados mostrando as vantagens e desvantagens em sua utilização e os principais danos causados à saúde e ao meio ambiente, bem como alternativas para evitar a poluição ambiental pelo mau uso desses. 


\section{TENSOATIVOS (SABÕES E DETERGENTES E CONGÊNERES)}

Os tensoativos são moléculas anfifílicas, ou seja, de dupla polaridade que tem a função de reduzir a tensão superficial entre a fase oleosa e aquosa facilitando a formação de emulsões (ATTWOOD E FLORENCE, 2003).

Os detergentes e seus congêneres são substâncias que têm como finalidade a limpeza e conservação de superfícies e pertencem à classe das substâncias tensoativas. Os principais exemplos dessas são: Detergentes; Alvejantes; Amaciante de Tecidos; Antiferruginosos; Ceras; Desincrustantes Ácidos e Alcalinos; Limpa Móveis, Plásticos, Pneus, Vidros; Polidores de Sapato, Superfícies Metálicas; Removedores; Sabões; Saponáceos e outros (ANVISA, 2010).

Os tensoativos podem ser classificados de acordo com a natureza de seu grupo hidrofílico (afinidade com a água) em: iônicos (catiônicos ou aniônicos), não-iônicos e anfóteros (ATTWOOD E FLORENCE, 2003).

Os sabões e os e detergentes são tensoativos aniônicos. A utilização desses tipos de tensoativos abrange uma enorme quantidade de produtos, desde xampus até aditivos alimentares.

Os sabões são substâncias obtidas através da reação de gorduras ou óleos com uma base (geralmente hidróxido de sódio ou potássio) dando origem ao sabão (sal). O sabão é uma substância biodegradável. A possibilidade de degradação das moléculas formadoras do sabão muitas vezes é confundida com o fato do produto ser poluente ou não. A biodegradabilidade não indica que um produto não causa danos ao meio ambiente, mas, que esse pode ser decomposto por microorganismos (geralmente bactérias aeróbicas), com facilidade e num curto espaço de tempo. A degradação da molécula de sabão ocorre em curto espaço de tempo ( \pm 24 horas).

O sabão causa poluição quando o utilizamos em nossas residências e misturado com a sujeira atinge rede de esgotos, alcançando rios, lagos ou oceanos sem tratamento prévio, podendo causar a eutrofização das águas. Tal fenômeno consiste em um enriquecimento da água com material orgânico e conseqüentemente aumento bactérias (anaeróbias), vários microorganismos, patológicos ou não, que se alimentam desse material. Tais bactérias consomem boa parte do oxigênio presente na água (processo de degradação) que deveria produzir $\mathrm{CO}_{2}$ (dióxido de carbono) e $\mathrm{H}_{2} \mathrm{O}$ (água) como produtos finais, porém, formam $\mathrm{CH}_{4}$ (metano), $\mathrm{H}_{2} \mathrm{~S}$ (ácido sulfídrico) e $\mathrm{NH}_{3}$ (amônia), que são mais tóxicos e prejudiciais ao meio ambiente (ZAGO NETO et al., 2010).

A vantagem na utilização do sabão está no fato desse ser sempre biodegradável e de ser produzido a partir de matéria-prima renovável (óleos e gorduras) além de sua degradação ocorrer em um curto espaço de tempo, o que facilita o processo de biodegradação (ZAGO NETO et al., 2010).

Os detergentes são produtos sintéticos produzidos a partir de derivados do petróleo. Possuem um poder de detergência maior que os sabões. Geralmente, os detergentes são compostos por diversos tensoativos (substância ativa) diferentes podendo conter tensoativos iônicos (catiônicos ou aniônicos), não-iônicos e anfóteros. Os tensoativos catiônicos não são compatíveis com os aniônicos quando se deseja um produto de limpeza. 
Os mais comuns tipos de tensoativos encontrados nos detergentes comerciais são: cocoamido propil betaína (anfótero), Lauril éter sulfato de sódio (aniônico), alquil benzeno sulfonato de sódio (aniônico) dentre outros. Nos detergentes neutros são encontrados além da mistura de tensoativos substâncias ou impurezas como o ácido sulfônico e os aditivos neutralizantes (ZAGO NETO et al., 2010).

Os sabões e detergentes possuem um grau de toxicidade que, embora baixo, pode ocasionar intoxicação que pode ser agravada dependendo do tipo de produto que a causa (ZAGO NETO et al., 2010).

Quando os sabões são excessivamente alcalinos, esses irritam a pele e quando seu uso é contínuo, podem causar dermatites. O contato prolongado do sabão com a mucosa ocular pode ocasionar lesões graves, e a sua ingestão pode causar distúrbios como vômitos, cólicas abdominais e diarréia (ZAGO NETO et al., 2010).

Os tensoativos aniônicos como o lauril benzeno sulfonato linear presentes nos detergentes são mais tóxicos que os sabões. A dose letal (DL50) deste composto, em ratos, por ingestão via oral, é de 800 a 300 miligramas $(\mathrm{mg})$ de detergente por quilograma (Kg) de cobaia (ZAGO NETO et al., 2010).

Os detergentes aniônicos, assim como os sabões, podem causar dermatites e irritam a mucosa ocular. Quando esses são ingeridos, os sintomas são evidenciados através do surgimento de náuseas seguidas por vômitos, cólicas abdominais e diarréia. A ingestão, para seres humanos, em quantidades pequenas (entre 0,1 e $1 \mathrm{~g} / \mathrm{Kg}$ de massa) não causa efeitos tóxicos (ZAGO NETO et al., 2010).

Os tensoativos catiônicos, devido às suas propriedades germicidas são muito utilizados como desinfetantes. Alguns desses surfactantes apresentam grau de toxicidade relativamente grande. O Cloreto de Dimetildiestearilamônio possui dose letal (DL50) em ratos, por via oral, que atinge o nível de $700 \mathrm{mg} / \mathrm{Kg}$ de cobaia. Estas substâncias podem causar distúrbios digestivos, hipotensão, confusão mental, fraqueza muscular, dificuldade respiratória, podendo levar o indivíduo à morte por asfixia, às vezes precedida por convulsões. Quando em contato com a pele, deve ser feita imediatamente a lavagem com água e sabão (ZAGO NETO et al., 2010).

Os surfactantes não-iônicos são os menos tóxicos, o alquiletoxilato, por exemplo, possui DL50 igual a 2.200-4.100 mg/Kg em experiências utilizando ratos induzidos à intoxicação por via oral. Estes tensoativos são mais utilizados em produtos cosméticos devido ao seu elevado custo de produção. Outros que também são utilizados em cosméticos são os tensoativos anfóteros, pois possuem crescente aplicação em xampus e cremes (ZAGO NETO et al., 2010).

\section{HIDRÓXIDO DE SÓDIO}

O hidróxido de sódio (nomenclatura química: hipoclorito de sódio) popularmente conhecido como soda caustica é utilizado por muitas donas de casa para desentupir sanitários, ralos de banheiros e outros ralos. Essa substância é bastante corrosiva. Em relação à toxidade pode produzir efeitos agudos por exposição em curto prazo quando em contato direto com a pele e causar queimaduras severas com ulceração profunda, cicatrizes permanentes e calvície. Pode também penetrar em camadas profundas da pele e a corrosão 
continuará até que seja removida. Com solução diluída, a sensação de irritação pode se prolongar por horas. Quando em contato com os olhos, os danos podem variar de irritação severa com cicatrizes leves a bolhas, desintegração, ulceração, cicatrizes severas e embasamento da visão. É possível que glaucomas e cataratas se desenvolvam com o tempo. Em casos severos pode causar cegueira (depende da concentração e tempo de contato). Sua ingestão pode produzir queimaduras corrosivas severas na boca, garganta e esôfago. Os sintomas incluem dores severas, vômito, diarréia, colapso, podendo ocasionar a morte. Os efeitos crônicos por exposição de longo prazo podem ser evidenciados na exposição da pele repetida e prolongada em concentrações líquidas baixas pode causar dermatite. Existem poucos relatos de doenças respiratórias crônicas causadas pela exposição repetida e prolongada à névoa de hidróxido de sódio. Não existe evidência de carcinogenicidade em humanos pela exposição ocupacional. $\mathrm{O}$ hidróxido de sódio não acumula no corpo.

O hidróxido de sódio (soda caustica) não deve ser utilizado nas residências, uma vez que, através dos esgotos pode alcançar rios, lagos e oceanos. Esse produto pode ser agudamente tóxico a vida aquática causando o aumento do $\mathrm{pH}$ a níveis tóxicos.

\section{ÁGUA SANITÁRIA}

São soluções aquosas à base de hipoclorito de sódio ou cálcio, com teor de cloro ativo entre 2,0 a $2,5 \% \mathrm{p} / \mathrm{p}$, durante o prazo de validade (máximo de 6 meses). Pode conter apenas hidróxido de sódio ou cálcio, cloreto de sódio ou cálcio e carbonato de sódio ou cálcio como estabilizante e ter ação como alvejante e de desinfetante de uso geral (ANVISA, 2010).

O hipoclorito de sódio (substância ativa da água sanitária) causa efeitos adversos à saúde humana, devido sua toxidade aguda. Quando em contato com olhos pode causar queimaduras graves e possível perda da visão. No contato dessa substância com a pele pode causar queimaduras graves. A ingestão acidental do hipoclorito de sódio pode causar queimaduras às mucosas da boca, esôfago e estômago. Outra forma de dano a saúde humana é através da inalação podendo causar irritação da via respiratória superior, resultando em tosse, sensação de engasgo e de queima na garganta e edema pulmonar (FISPQ, 2010).

Os danos ambientais causados pelo hipoclorito de sódio são vários: provoca a poluição dos rios, da flora, do solo, do ar e prejudica a fauna. Essa substância também oferece perigos físicos e químicos que podem ser evidenciados através do contato com metais (reage) liberando gás explosivo (hidrogênio). Pode ser um agente oxidante, reage com produtos orgânicos, podendo resultar fogo e é incompatível com agentes redutores (amônia, éter) (FISPQ, 2010).

Soluções de Hipoclorito de Sódio são razoavelmente estáveis em concentrações abaixo de $1 \%$. A estabilidade diminui com concentração, calor, expedição a luz, diminuição do pH e contaminação com metais pesados como níquel, cobalto, cobre e ferro que agem como catalisadores (liberação de oxigênio) (FISPQ, 2010).

A forma correta de manuseio seguro é usando óculos químicos e protetores faciais, luvas e vestimentas de proteção (FISPQ, 2010). Muitas pessoas utilizam a água sanitária sem 
nenhuma proteção e dessa maneira estará absorvendo essa substância através da pele.

\section{PRODUTOS DESINFESTANTES (INSETICIDAS, REPELENTES)}

Os inseticidas, quando utilizados de acordo com as instruções, não têm riscos imediatos para o consumidor. Porém, em longo prazo, alguns podem ser cancerígenos e desreguladores endócrinos. Uma das substâncias encontradas nos inseticidas é o Butóxido de Piperonilo (PBO), um agente possivelmente cancerígeno e que provoca náuseas, diarréia e problemas respiratórios. Assim, os inseticidas que contém esse tipo de substância devem ser evitados.

Os biocidas possuem na sua composição algumas substâncias que podem causar efeitos graves na saúde humana. Nos inseticidas utilizados para eliminar mosquitos, moscas, formigas, insetos, aerossóis antipulgas e produtos antitraça encontramos substâncias maléficas a saúde humana, tais como a Tetramina, a Permetrina, a Imiprotrina, a Cipermetrina e os Piretrinóides. O tipo de contato com essas substâncias causam perturbações nos olhos e ao nível digestivo, reações alérgicas cutâneas ou respiratórias.

A substância paradiclorobenzeno utilizada para matar traças pode originar irritação nos olhos, pele e mucosas do nariz, distúrbios neurológicos e do comportamento, assim como danos no fígado.

A Dietiltoluamida (DEET) está presente nos repelentes para mosquitos. Em doses elevadas e usadas com freqüência, pode causar distúrbios neurológicos e crises de asma e os recémnascidos são muito sensíveis a este produto (PROTESTE, 2010).

A naftalina, usada contra as traças, provoca náuseas e dor de cabeça e é potencialmente cancerígena. Além disso, as bolinhas podem ser confundidas com rebuçados pelas crianças.

A eficiência dos repelentes depende da temperatura e umidade do ambiente, transpiração, vestuário, quantidade de produto e atividade (desporto, etc.). Os repelentes, ainda não apresentam estudos conclusivos sobre a sua toxicidade em longo prazo. Mas, o fato de não haver informações não significa que sejam inócuos.

A melhor forma de proteger a saúde e o meio ambiente é evitar o uso desses produtos, substituindo por alternativas eficazes como o uso de mosquiteiros e uma limpeza eficaz do ambiente, para evitar o aparecimento desses insetos (PROTESTE, 2010).

\section{PERCEPÇÃO AMBIENTAL E ESTRATÉGIAS SUSTENTÁVEIS DE USO DE PRODUTOS QUÍMICOS A PARTIR DA VISÃO DE DONAS DE CASA DO BAIRRO DE NOVA DESCOBERTA EM NATAL/RN}

A análise da percepção ambiental dos moradores do bairro de Nova Descoberta em Natal ocorreu por meio da aplicação de entrevistas e análise dos discursos de donas de casa, sobre a utilização dos produtos químicos domiciliares e destinação final dos mesmos.

Para a análise dos dados e discussão das falas dos sujeitos da pesquisa, organizamos os questionários numa ordem numérica por meio da seqüência dos algarismos arábicos, como 
forma de preservar o anonimato dos nomes, pontos de vista e opiniões de cada um dos entrevistados.

As entrevistas foram realizadas com 10 donas de casa, com faixa etária compreendida entre 30 e 58 anos, sendo a idade média 43 anos. Quanto ao nível de escolaridade dos entrevistados, a pesquisa revelou que $80 \%$ possuem o Ensino Médio completo, $10 \%$ Ensino Médio incompleto e 10\% concluíram o Ensino Fundamental.

Foram realizadas perguntas quanto ao tempo em que residiam no domicilio e foi constatado que $20 \%$ moravam a menos de 5 anos, $30 \%$ moravam entre 5 e 10 anos, $50 \%$ moravam mais de 10 anos. Quanto à renda familiar, 60\% responderam que recebiam até 1 salário mínimo, 30\% recebiam entre 1 e 2 salários mínimos, $10 \%$ recebiam mais de 2 salários mínimos. Foram realizadas perguntas também sobre a ocupação dessas e as respostas obtidas foram que $20 \%$ são profissionais liberais (costureiras) e $80 \%$ trabalhavam no comércio.

Quando foram inquiridos sobre a utilização dos produtos químicos domiciliares quanto aos seus efeitos tóxicos, $80 \%$ não perceberam efeitos tóxicos e nem sabia que esses produtos poderiam causar tais efeitos (irritação na pele e nos olhos, dores de cabeça e náuseas) na manipulação dos produtos químicos domiciliares e $20 \%$ perceberam alguns desses sintomas ao manipular alguns tipos de produtos químicos. As pessoas que não observaram tais efeitos relataram o discurso da seguinte forma:

“E existe efeitos tóxicos nesses produtos que a gente usa em casa?" (entrevistados 1, 2 e 5)

"Nunca ouvir falar que os produtos que a gente usa em casa fossem tóxicos" (entrevistados $7,9,10)$

Segundo os moradores entrevistados, a freqüência da coleta de lixo no bairro ocorre três vezes na semana (terça, quinta e sábado). Cerca de $80 \%$ das entrevistadas relataram não prestar atenção aos horários de coleta e apenas $20 \%$ disseram que colocam o lixo próximo dos horários de coleta. Embora o serviço de coleta seletiva seja oferecido, nenhuma delas afirmou realizar coleta seletiva.

Questionou-se também, quanto ao destino dos produtos químicos tóxicos e perigosos (pilhas, baterias, lâmpadas de luz fluorescentes, latas de tintas, óleos, solventes e similares) e se essas donas de casas sabiam dos malefícios causados ao meio ambiente por dispô-los de maneira incorreta. Todas as entrevistadas responderam que são esse tipo de lixo são dispostos no lixo comum, como observado nos discursos a seguir:

"Nunca parei para pensar nisso" (entrevistada 1)

"Não sabia que não poderia jogar esses produtos no lixo comum" (entrevistadas 2,5,7,8,9 e 10)

"Jogava no lixo comum porque não sei outro lugar que eu possa jogar para não poluir" (entrevistadas 3,4 e 6) 
Quanto ao resto de óleo de cozinha utilizado, 90\% das donas de casa afirmaram que despejam na pia, ou seja, diretamente na rede de esgoto doméstico, e 10\% apenas colocam em um recipiente fechado e joga no lixo comum.

Em relação ao armazenamento dos produtos de limpeza e remédios (locais que não possam ser alcançados por crianças) foi constatado que $80 \%$ armazenam longe do alcance de crianças e $20 \%$ relataram que não existem locais apropriados em que as crianças não possam alcançar. Em relação a acidentes por ingestão ou inalação de algum produto químico $30 \%$ relataram já ter ocorrido ingestão de medicamentos e produtos químicos de limpeza e $70 \%$ relataram não ter acontecido nenhum acidente.

Em relação ao destino dos esgotos domésticos foi relatado que embora exista o serviço de saneamento, as donas de casa entrevistadas não fizeram ainda a ligação e o sistema ainda é o de fossa. Os moradores também foram questionados se sabiam a função do esgotamento sanitário no bairro. Desses, apenas $20 \%$ responderam não saber exatamente a função contra os $80 \%$ restantes, como observado através dos discursos transcritos abaixo:

"Realmente já tem o serviço de esgotamento mais ninguém fez ligação. Serve para coletar o esgoto" (entrevistadas 1 e 9)

"O serviço é oferecido mas eu ainda nem sei como fazer a ligação. O esgotamento sanitário serve para que o esgoto seja coletado, seja tratado acabando com as fossas nas residências, acabando com o mau cheiro e os insetos que aparecem por causa do esgoto." (entrevistadas $2,7,8$ e 10$)$

"Ainda não fiz a ligação. Mas sei que serve para coletar o esgoto e retirar também os esgotos que correm rua a baixo porque tem casa que liga o esgoto das casas para rua. Além disso, contribui para higiene e diminuição da proliferação de insetos." (entrevistadas 3 e 4)

Em relação aos períodos de chuva foi relatado que a maioria das ruas fica alagada. Foi perguntado se elas saberiam o porquê disso acontecer e $60 \%$ responderam que achavam que era por causa do lixo que é jogado nas ruas e devido o lixo domiciliar ainda não ter sido coletado e também poderia ser que o lixo tenha sido arrastado de outros lugares. $40 \%$ não souberam responder a essa questão.

Percebe-se que as respostas obtidas nas entrevistas refletem a pouca informação da população em relação aos produtos químicos domiciliares (manipulação correta, toxidade, possíveis problemas de saúde e ambientais causados por tais produtos). Além disso, ficou evidenciada a disposição inadequada dos produtos químicos domiciliares tóxicos e perigosos e a falta de planejamento ambiental domiciliar. Tais constatações mostram a necessidade de se criar estratégias sustentáveis.

Por meio dessas respostas é possível perceber que as pessoas apontam a higiene e a presença de vetores como função da falta de ligação ao esgotamento sanitário do bairro e maus hábitos ambientais (jogar lixo nas ruas, dispor o lixo em horários diferentes da coleta). Vale ressaltar que, essas pessoas, convivem diariamente com as águas servidas (esgoto) na frente suas residências em decorrência da falta de captação de resíduos líquidos a comunidade o que demonstra uma preocupação quanto à qualidade de vida dos residentes. 
As entrevistas realizadas com as donas de casa confirmaram as hipóteses preliminares dessa pesquisa quanto aos problemas enfrentados devido à falta de planejamento ambiental domiciliar.

As estratégias sustentáveis são apontadas dentro da proposta de planejamento ambiental que engloba uma série de ações as quais contribuirá para melhoria da qualidade de vida dos moradores do bairro de Nova Descoberta e estão apresentadas em um plano de trabalho (planejamento ambiental).

As estratégias sustentáveis são realizadas dentro do planejamento ambiental que compreende as mudanças de maus hábitos evidenciados dos moradores do bairro e a proposição de medidas mitigadoras (corretivas e preventivas). As principais medidas mitigadoras são: minimização da produção de lixo domiciliar (corretiva), disposição do lixo em horários próximo os da coleta (minimização de vetores causadores de doenças) uso adequado de produtos químicos domiciliares (prevenção de acidentes e doenças), observação da validade dos produtos e remédios (prevenção), disposição correta de produtos químicos domiciliares tóxicos e perigosos (minimização da poluição). Tais ações irão contribuir para preservação do meio ambiente e realização do planejamento ambiental domiciliar.

\section{AVALIAÇÃO AMBIENTAL DAS RESIDÊNCIAS}

Para uma melhor avaliação ambiental das residências do Bairro de Nova Descoberta foram realizadas perguntas nas entrevistas e questionários que abordaram os seguintes temas: principais produtos químicos de uso domiciliar utilizados pelas donas de casa, como esses são dispostos no meio ambiente (lixo comum ou outros), se as donas de casa têm conhecimento de locais adequados onde poderiam destinar o lixo tóxico perigoso, se fazem coleta seletiva, se possuem conhecimento aonde entrar em contato para que seja realizada a destinação correta, se utilizam produtos clandestinos, e os principais hábitos observados pela comunidade que afetam a saúde e o meio ambiente.

Houve a necessidade de se ter um diagnóstico ambiental da área residencial a partir dos diferentes aspectos analisados: desperdício de água e alimentos consumidos (aumento de lixo) se é aproveitada cascas de frutas e verduras (redução da geração de lixo); se a população costuma jogar lixo na rua; quais os principais produtos químicos domiciliares utilizados; se são obedecidas às recomendações dos rótulos dos produtos e como são dispostos e se são utilizados produtos clandestinos.

Nas residências avaliadas através da pesquisa, ficou evidente a necessidade de se mudar hábitos, para que houvesse segurança da comunidade e do meio ambiente. Constatou-se que, pequenas mudanças nos hábitos como, por exemplo, evitar desperdício de comida e água traz benéficos para o meio ambiente (redução da produção de lixo). Observou-se que, a iniciativa de propor o planejamento ambiental ordenado começando da nossa casa, estimulou todos os componentes da residência a realizá-lo também nos demais ambientes freqüentados, através de atitudes que garantem o desenvolvimento sustentável e a participação social, estimulando o debate sobre o uso dos recursos naturais, de forma racional e sustentável. 


\section{OBJETIVOS E METAS}

A fase organizacional foi realizada através de uma avaliação ambiental nas residências de donas de casa do bairro de Nova Descoberta na cidade de Natal/RN, tendo como principais objetivos e metas:

- Preservação da saúde da comunidade e meio ambiente;

- Aumentar a segurança nas residências;

- Estimular a consciência ambiental da comunidade;

- A partir da percepção de donas casas e das informações presentes nesse trabalho promover a educação ambiental

\section{DEFINIÇÃO DOS INDICADORES}

Através de uma avaliação criteriosa em todo o ambiente residencial, verificou-se que alguns indicadores seriam eficientes para o acompanhamento da pesquisa, para cumprimento da fase do inventário, como por exemplo:

1. No intuito de preservar o meio ambiente:

- Colocar o lixo doméstico próximo ao horário de coleta para evitar insetos vetores de doenças para a comunidade;

- Adotar práticas de separação de lixo, ou seja, realizar a coleta seletiva;

- Dispor corretamente os produtos químicos perigosos tais como: lâmpadas fluorescentes, latas ou resto de tintas, óleos, solventes e similares, pilhas e baterias, medicamentos impróprios para o consumo (prazo de validade vencido) termômetros, dentre outros, nos locais de coleta;

- Armazenar o óleo utilizado no preparo dos alimentos em um depósito e entregar em postos de coleta para reutilização;

- Minimizar o desperdício de água e produção de lixo

2. Com o objetivo de aumentar a segurança da residência:

- Verificação do prazo de validade dos produtos químicos e utensílios domésticos;

- Registro dos acidentes ocorridos dentro de casa tais como ingestão de produtos químicos acidental por crianças para evitar e servir de alerta no futuro.

3. Planejamento para evitar desperdícios de alimentos e produtos químicos:

- Comprar somente o necessário de alimentos para o consumo das pessoas da residência (diminuição de restos de comida);

- Reaproveitamento de cascas de frutas e verduras em receitas nutritivas; 
- Comprar somente o necessário de produtos químicos e utilizá-los segundo as recomendações deforma a evitar desperdícios (evitar prazos de validade vencidos).

\section{TEMPO DE IMPLANTAÇÃO DAS ALTERNATIVAS PROPOSTAS}

Algumas alternativas podem ser realizadas de forma imediata, outras conforme o planejamento ambiental sugere, necessita de tempo, que foi classificado como de imediato, médio e longo prazo.

\section{ANÁliSE DETALHADA DAS ALTERNATIVAS PROPOSTAS NO PLANEJAMENTO AMBIENTAL PROPOSTO}

Na Tabela 2, segue detalhada a situação atual de cada fator analisado, de acordo com o objetivo e alternativas propostas da pesquisa, a estimativa do tempo de obtenção de resultados promissores, como parte das fases de diagnóstico ambiental, propositiva e de execução.

Tabela 2: Modelo de Planejamento Ambiental Residencial Proposto a partir das Informações de Donas de Casa do Bairro de Nova Descoberta.

\begin{tabular}{|c|c|c|c|}
\hline Objetivos & $\begin{array}{c}\text { Alternativas } \\
\text { propostas } \\
\end{array}$ & $\begin{array}{c}\text { Situação } \\
\text { atual }\end{array}$ & $\begin{array}{c}\text { Tempo de obtenção } \\
\text { de resultados promissores } \\
\end{array}$ \\
\hline \multirow[t]{3}{*}{$\begin{array}{c}\text { Preservar o } \\
\text { meio ambiente }\end{array}$} & $\begin{array}{l}\text { Colocar o lixo próximo ao horário de } \\
\text { Coleta }\end{array}$ & $\begin{array}{l}\text { Não } \\
\text { eficiente. }\end{array}$ & Imediato \\
\hline & $\begin{array}{l}\text { Realização de } \\
\text { coleta seletiva }\end{array}$ & $\begin{array}{l}\text { Não } \\
\text { eficiente. }\end{array}$ & $\begin{array}{l}\text { Médio ou longo } \\
\text { Depende da residência que ainda não } \\
\text { tem um sistema de coleta específico. }\end{array}$ \\
\hline & $\begin{array}{l}\text { Dispor corretamente } \\
\text { os produtos químicos } \\
\text { perigosos }\end{array}$ & $\begin{array}{l}\text { Não } \\
\text { eficiente. }\end{array}$ & Imediato \\
\hline $\begin{array}{c}\text { Aumentar } \\
\text { a segurança }\end{array}$ & $\begin{array}{l}\text { Verificação do prazo de validade } \\
\text { dos produtos e utensílios domésticos; }\end{array}$ & Eficiente. & $\begin{array}{l}\text { Imediato } \\
\text { Guardar os produtos químicos em } \\
\text { lugares adequados longe do } \\
\text { alcance de crianças, }\end{array}$ \\
\hline \multirow[b]{2}{*}{$\begin{array}{l}\text { Planejamento } \\
\text { para evitar } \\
\text { desperdícios } \\
\text { (aumento de } \\
\quad \text { lixo) }\end{array}$} & Registro dos acidentes ocorridos. & A realizar & $\begin{array}{l}\text { Médio } \\
\text { Elaboração de uma tabela para registro } \\
\text { dos acidentes. }\end{array}$ \\
\hline & $\begin{array}{l}\text { Acompanhamento do valor } \\
\text { gasto com alimentação } \\
\text { Acompanhamento do valor gasto } \\
\text { com produtos químicos. }\end{array}$ & A realizar. & $\begin{array}{l}\text { Médio } \\
\text { Cálculo da quantidade exata de alimentos } \\
\text { para consumo ideal das pessoas das } \\
\text { residências; } \\
\text { Organização do orçamento para comprar } \\
\text { Apenas a quantidade necessária de produtos } \\
\text { químicos (evitar desperdícios) }\end{array}$ \\
\hline
\end{tabular}

Fonte: Pesquisa de Campo, 2010. 


\section{CONSIDERAÇÕES FINAIS}

Após as análises das percepções de donas de casa do bairro de Nova Descoberta em Natal/RN sobre a utilização dos produtos químicos domiciliares foi possível propor estratégias sustentáveis. Como estratégia sustentável foi proposto o desenvolvimento do planejamento ambiental domiciliar que irá contribuir para mudanças na qualidade de vida e minimização dos impactos ambientais da comunidade do bairro de Nova Descoberta a fim de alcançar a sustentabilidade.

Através da percepção delas foram diagnosticados e avaliados os impactos ambientais. A investigação possibilitou propor medidas mitigadoras (corretivas e preventivas) tais como: a minimização da produção de lixo domiciliar, disposição do lixo em horários próximo os da coleta (minimização de vetores causadores de doenças) uso adequado de produtos químicos domiciliares (prevenção de acidentes e doenças), disposição correta de produtos químicos domiciliares tóxicos e perigosos (minimização da poluição). Tais ações irão contribuir para preservação do meio ambiente e realização do planejamento ambiental domiciliar.

A pesquisa permitiu uma obtenção de um conhecimento amplo e detalhado da situação problema, diagnosticada no bairro de Nova Descoberta. Dessa forma, as donas de casa perceberam a necessidade de mudanças de hábitos que refletirá na qualidade de vida e minimização dos impactos ambientais.

\section{REFERÊNCIAS}

1. ATWOOD, D.; FLORENCE, A. T.; Princípios físico-químicos em farmácia. São Paulo: Editora da Universidade de São Paulo, 2003.

2. BRASIL. Associação brasileira de normas técnicas - ABNT. Informes técnicos: dispõe sobre resíduos sólidos - classificação. Disponível em:< http://www.aslaa.com.br/legislacoes/NBR\%20n\%2010004-2004.pdf >. Acesso em: 18 jul. 2004.

3. BRASIL. Centro Colaborador em Vigilância Sanitária da Escola Nacional de Saúde Pública Sérgio Arouca da Fundação Oswaldo Cruz - CECOVISA. Lixo tóxico domiciliar. $\quad O$ que fazer?. Disponível em:< http://www4.ensp.fiocruz.br/visa/nossaroducao/publicacoes.cfm?tipo=442\&pub=786 $>$.Acesso em 22 fev. 2010.

4. BRASIL. Conselho Nacional do Meio Ambiente- CONAMA. Resolução $n^{\circ}$ 401, de 4 de novembro de 2008. Publicada no DOU n ${ }^{\circ} 215$, de 5 de novembro de 2008, Seção 1, página 108-109. Disponível em: < http://www.mma.gov.br/port/conama/legiabre.cfm?codlegi=589>. Acesso em: 12 fev. 2010.

5. BRASIL. Conselho Nacional do Meio Ambiente- CONAMA. Resolução ${ }^{\circ}{ }^{5}$, de 5 de agosto de 1993. Publicada no DOU n 166, de 31 de agosto de 1993, Seção 1, páginas 12996-12998. Acesso em: < http://www.mma.gov.br/port/conama/legiabre.cfm?codlegi=130>. Acesso em: 29 de jun de 2010.

6. BRASIL. Lei ${ }^{\circ}$ 9.605, de 13 de fevereiro de 1998. Publicada no Diário Oficial de 13 de fevereiro de 1998, seção 1, página 1. Disponível em: 
http://www.internationalwildlifelaw.org/LeideCrimesAmbientais.htm. Acesso em 22 fev. 2010.

7. BRASIL. Ministério da Saúde. Agência Nacional de Vigilância Sanitária - ANVISA. Produtos saneantes. Disponível em: < http://portal.anvisa.gov.br/wps/portal/anvisa/home/saneantes >. Acesso em: 22 de fev. de 2010.

8. BRASIL. Ministério da Saúde. Agência Nacional de Vigilância Sanitária - ANVISA. Orientações para os consumidores de saneantes. Disponível em: < http://www.anvisa.gov.br/saneantes/cartilha.htm> Acesso em 10 marc. 2010.

9. BRANCO, S. M. Natureza e agroquímicos. São Paulo: Moderna, 1990.

10. BRASIL. Secretaria do Meio Ambiente e Urbanismo de Natal - SEMURB. Mapas temáticos. Disponível em: <http://www.natal.rn.gov.br/semurb/paginas/ctd106.html>. Acesso em 10 de jul. de 2010.

11. FELICONIO, A. E. Produtos de limpeza: o desafio de limpar a casa sem poluir o planeta - Parte II. em: $<$ http://www.sitiodomoinho.com/jornal/powervoice/DefaultNewsShow.asp?Edito ria $=6 \&$ Noticia $=72>$. Acesso em: 27 fev. 2010.

12. FERNANDES, R. S., SOUZA, V. J., PELISSARI, V. B., FERNANDES, S.T. Uso da percepção ambiental como instrumento de gestão em aplicações ligadas às áreas educacional, social e ambiental. Rede Brasileira de Centros de Educação Ambiental. Rede CEAS. Noticias, 2009. Disponível em: <http://www.redeceas.esalq.usp.br/noticias/Percepcao_Ambiental.pdf > Acesso em: 12 jan. 2009.

13. FERREIRA, P. C. Percepção ambiental na estação ecológica Juréia - Itatins. Dissertação (Mestrado em Ciência Ambiental), São Paulo: Universidade de São Paulo, 2005.

14. FISPQ - International Sport for All Federation. Hipoclorito de sódio. Disponível em: <http://www.caii.com.br/downloads/fispq-hipocloritodesodio.doc>. Acesso em: 22 fev. 2010.

15. GERMANO, P.M.; GERMANO, M.I.S., Higiene e vigilância sanitária de alimentos: qualidade da matéria-prima, doenças transmitidas por alimentos e treinamento de recursos humanos. São Paulo: Manole, ed. 3, 986 p, 2008.

16. MICHEL, R.O. Toxicologia ocupacional. Rio de Janeiro: Revinter LTDA, 2000.

17. MILARÉ, E. Direito ambiental: a gestão ambiental em foco. São Paulo: RT, Ed.6, 2009.

18. MILlER Jr. G T.. Ciência ambiental. (Tradução da $11^{\mathrm{a}}$ Edição). São Paulo: Thompson Pioneira, 2007.

19. MOREIRA, R. J. Ecologia e economia política: Meio Ambiente e Condições de Vida. In: Anais.Congresso XXIX da SOBER, São Paulo, 1991.

20. PHILIPPI Jr, A. Saneamento, saúde e ambiente: fundamentos para um desenvolvimento sustentável. Barueri: USP, p.663-688, 2005.

21. PROTESTE. Insetividas e repelentes: use, mas não abuse. Disponível em: $<$ http://www.deco.proteste.pt/saude/insecticidas-e-repelentes-use-mas-nao-abuse486811.htm>. Acesso em: 25 fev. 2010. 
22. RIBEIRO, I. O destino do óleo de cozinha. Disponível em:< http://www.biodieselbr.com/noticias/em-foco/destino-oleo-cozinha-27-07-09.htm>. Acesso em: 27 fev. 2010.

23. SÁ, C de P. A Construção do objeto de pesquisa em representações sociais. Rio de Janeiro: EDUERJ, 1998.

24. SANTOS, R.F. Planejamento ambiental: teoria e prática. São Paulo: Oficina de Textos, 2004.

25. SCHVARTSMAN, S., Produtos químicos de uso domiciliar: Segurança e riscos toxológicos. São Paulo: Almed, ed. 2, p. 182, 1988.

26. SILVA, V. P. Métodos e técnicas de pesquisa. Natal: Centro Federal de Educação Tecnológica do Rio Grande do Norte (CEFET-RN), 2007.

27. SLOCOMBE, D.S. Environmental planning, ecosystem science, and ecosystem approaches for integrating environment and development. Vironmental Management, 17 (3), p. 289-303, 1993.

28. SUSTAINABLE STRATEGIES. Sustainable Strategies. Disponível em: http://www.sustainablestrategies.com/dnn/. Acesso em 12 jul. 2010.

29. TUAN, Y. Topofilia: um estudo da percepção, atitudes e valores do meio ambiente. São Paulo: Difel, 1980.

30. TERAMUSSI, M. T. Percepção de estudantes sobre o Parque Ecológico do Tietê, São Paulo- SP. Dissertação (Mestrado em Ciência Ambiental), São Paulo: Universidade de São Paulo, 2008.

31. ZAGO NETO, O.G.; DEL PINO, C. J. Trabalhando a química dos sabões e detergentes. Disponível em: http://www.iq.ufrgs.br/aeq/html/publicacoes/matdid/livros/pdf/sabao.pdf $>$. Acesso em: 20 fev. 2010. 